\title{
Geostatistical characterisation of centimetre-scale spatial structure of in vivo fluorescence
}

\author{
Raechel L. Waters*, James G. Mitchell, Justin Seymour \\ School of Biology, Flinders University, GPO Box 2001, South Australia 5001, Australia
}

\begin{abstract}
We present the first quantitative evidence of 2-dimensional non-random spatial structure for in vivo fluorescence distributions measured at scales of centimetres. To determine the presence of non-random structure and to quantify levels of spatial complexity, 2 common geostatistical analysis techniques, namely Moran's I spatial autocorrelation statistic and single-dimension fractal analysis, were employed. Samples were collected at 4 and $2 \mathrm{~cm}$ resolution from 2 coastal environments in South Australia; $50 \%$ of the distributions were spatially autocorrelated and $60 \%$ exhibited fractal scale dependence (with a fractal dimension, $D_{\mathrm{F}}$, ranging from 1.54 to 1.89). Comparison of distributions sampled in the horizontal and vertical indicate that structural complexity is equally important in both planes. Structural complexity was greater at $2 \mathrm{~cm}$ than at $4 \mathrm{~cm}$, suggesting that structure may arise at or below the $2 \mathrm{~cm}$ scale. This observation is in direct conflict with the general assumption that turbulence homogenises distributions at these scales.
\end{abstract}

KEY WORDS: Two-dimensional sampling · Moran's I-statistic $\cdot$ Correlogram · Fractal analysis Resale or republication not permitted without written consent of the publisher

\section{INTRODUCTION}

The non-random spatial structure of phytoplankton distributions is the focus of an extensive body of theoretical and empirical research (Steele 1978, Powell \& Okubo 1994). Fluctuations in phytoplankton biomass in turbulent environments, estimated by Fourier power spectral analysis (Platt 1972, Platt \& Denman 1975), are similar to the power spectra for fully developed isotropic turbulence and passive tracers over scales of kilometres to metres (Kolmogorov 1941, Okubo 1978). However, below $1 \mathrm{~m}$, turbulence is predicated to randomise phytoplankton spatial distribution (Okubo 1980, Denman \& Powell 1984). Recently, this paradigm has been challenged. Multifractal analysis of coastal, fluorescence time-series and temperature showed non-random spatial organisation of phytoplankton down to $0.4 \mathrm{~m}$ (Seuront et al. 1996, Lovejoy et al. 2001). Similar structure has also been reported in linear profiles of fluorescence analysed by single fractal techniques (Waters \& Mitchell 2002).

Here we extend the observation of spatial structure from 1 dimension (Waters \& Mitchell 2002) to 2 dimen- sions. The existence of 2-dimensional non-random structure has been implied from the results of replicate linear profiles (Mitchell \& Fuhrman 1989, Owen 1989, Waters \& Mitchell 2002) and 2-dimensional optical sampling techniques (Jaffe et al. 1998, Katz et al. 1999, Hobson et al. 2000, Franks \& Jaffe 2001). While these results extend our understanding of the variability of distributions at the centimetre scale, they do not provide an explicit measure of structure that allows comparison between studies. We address this need here.

To date, instrumentation is not available for centimetre-scale studies that is capable of generating long datasets comparable to those available to biological and physical oceanographers working on scales of metres to kilometres. We, therefore, use less dataintensive geostatistical techniques in preference to traditional (e.g. spectral analysis) and more recently introduced non-linear and multifractal techniques (e.g. Pascual et al. 1995, Seuront et al. 1996, 1999, Strutton et al. 1996, Currie et al. 1998, Lovejoy et al. 2001). The specific aims of the study were to determine whether 2-dimensional fluorescence distributions, sampled at sampling intervals of centimetres, were non-random. 
We sampled in the horizontal and vertical planes to investigate whether spatial structure was orientationdependent. We found non-random distributions in both sampling planes and at 4 and $2 \mathrm{~cm}$ resolution.

\section{MATERIALS AND METHODS}

Sample collection. Samples were collected with 2 pneumatically operated syringe-array devices (adapted from the designs of Baker et al. 1985). Device I consisted of a $7 \times 7$ grid of $12 \mathrm{ml}$ volume syringes mounted on a copper frame with an inter-sample distance of $4 \mathrm{~cm}$. Device II had the same syringe configuration as Device I, but with a $6 \mathrm{ml}$ sample volume and intersample distance of $2 \mathrm{~cm}$. Phytoplankton biomass, measured as in vivo fluorescence, was determined on site, from dark-adapted $5 \mathrm{ml}$ subsamples, using a Turner Design AU-10 field fluorometer.

Sampling took place in 2 coastal environments in Gulf St. Vincent, South Australia, during the period October 1998 to July 1999. The Port River $\left(34^{\circ} 44^{\prime} \mathrm{S}\right.$, $138^{\circ} 28^{\prime} \mathrm{W}$ ) site has a mean salinity of $32.5 \mathrm{ppt}$ and a mean chlorophyll a content of $20 \mu \mathrm{g} \mathrm{l}^{-1}$ (T. Ault unpubl. data). The site is tidally flushed (max. tidal excursion $=$ $2.5 \mathrm{~m}$ ) and has minimal freshwater input. Samples were collected from a small boat pontoon (mean water depth $=5 \mathrm{~m})$. The Port Noarlunga reef $\left(35^{\circ} 09^{\prime} \mathrm{S}, 138^{\circ} 28^{\prime} \mathrm{W}\right)$ site is partially protected by a rock reef (200 m offshore), but experiences full exchange with the waters of the open gulf at high tide. This site is characterised by a mean salinity of $37.0 \mathrm{ppt}$ and a mean chlorophyll $a$ content of $0.2 \mathrm{\mu g} \mathrm{l}^{-1}$ (Flinders University unpubl. data). Samples were collected from the western end of the Port Noarlunga jetty (pier), approximately $150 \mathrm{~m}$ from shore, where the water depth is 6 to $8 \mathrm{~m}$.

To characterise the physical environment at each site, 3 min of 3-dimensional velocity data were collected before each sampling event with a Sontek field acoustic doppler velocimeter. These data were then extracted and decontaminated (for spikes or missing data) using WinADV software (Tony Wahl, US Bureau of Reclamation). Due to low turbidity at Port Noarlunga, the $u$ (parallel to flow) and $v$ (transverse to flow, horizontal) velocity-data components were of poor quality and discarded. Therefore, only the $w$ (transverse to flow, vertical) velocity component, measured perpendicular to the direction of flow, was used. The intensity of mixing was quantified as the root mean square of the fluctuating component of $w_{1} w^{\prime}$ (Eq. 1 adapted from Kundu 1990):

$$
W^{\prime}=\left[\overline{(w-\bar{W})^{2}}\right]^{\frac{1}{2}}
$$

Comparison of sample orientation. To determine whether the structure of heterogeneity of horizontal and vertical phytoplankton distributions differed, pairs of sample sets were taken in the Port River on 3 occasions using Device I (4 cm inter-sample distance) only. The sampling device was orientated in the horizontal plane at $10 \mathrm{~cm}$ depth, with the syringes facing downwards, and in the vertical plane at 10 to $34 \mathrm{~cm}$ depth, with the syringes facing upstream. Horizontal and vertical sampling events were separated by approximately $90 \mathrm{~min}$.

Comparison of sampling scale and sampling sites. To investigate the influence of scale on phytoplankton distributions, pairs of sample sets were taken on 3 occasions at the Port River site using both sampling devices. On each occasion, sampling was made first with Device I, followed approximately 90 min later by Device II. At each sampling, the sampling device was horizontal at $10 \mathrm{~cm}$ depth, with the syringe openings downwards. Samples were also collected in this manner from the Port Noarlunga site on 2 occasions.

Statistical analysis. Moran's I-statistic (autocorrelation analysis), correlograms and single-dimension fractal geometry were employed to identify whether distributions were non-random and therefore spatially structured. Before all analyses, data were normalised to zero mean and unit variance.

Moran's I-statistic: Moran's I-statistic (Moran 1950) quantifies the level of spatial autocorrelation in a distribution by comparing the measured value of geographically neighbouring samples in terms of the individual sample deviation from the mean of all observations. We used a weighted form of the statistic (Cliff \& Ord 1981) such that the comparison of geographically near samples has a greater contribution to the calculation of $I$ than geographically remote samples:

$$
I=n \sum_{i j}^{n} W_{i j} z_{i} z_{j} / W \sum_{i=1}^{n} z_{i}^{2}
$$

where $n=$ number of samples, $x_{i}=$ variate value in sample $i, z_{i}=x_{i}-\bar{X}$, and $w_{i j}=$ the weight applied to the comparison for $i$ and $j_{i}$ here we use the inverse of the distance between locations:

$$
W_{i j}=\left(1 / d_{i j}\right) \text { and } W=\sum_{i j}^{n} w_{i j}
$$

To determine whether the sampled fluorescence distributions were globally autocorrelated, an omnidirectional (the sum of all $i, j$ comparisons) global Moran's I-statistic (Eq. 2) was calculated for each data set. Calculated global Moran's I-values were tested for statistical significance against the assumption of randomness (expected value $I=-[n-1]^{-1}$ ) following the method of Sokal \& Oden (1978), described in detail by Cliff \& Ord (1981). Significant global $I$-values therefore indicate non-randomness or the presence of spatial structure in the distribution. The values of significant $I$-statistics 
provide information on the nature of the spatial distribution. A positive spatial autocorrelation statistic indicates dependence between samples that are geographically close, whereas a negative value indicates dependence between geographically distant samples. Global I calculations were performed utilising Crimestat software (Ned Levine \& Associates).

To explore the spatial relationship between sample values further, mean Moran's I-statistics were calculated for all sample pairs separated by a specified separation distance. All possible sample pairings were considered, including horizontal, vertical and diagonal comparisons. The mean $I$-value for each set of pairs separated by a specific separation distance, termed the lag distance $(h)$, was used to construct a correlogram (see e.g. Figs. 3 \& 7), which is a plot of the relationship between spatial autocorrelation and geographical distance. For these calculations the weight parameter $w_{i j}$ in Eq. (2) was binary, taking a value of 1 for sample pairs that were separated by the identified separation distance or lag, and zero for all other pairings. Only lag distances with $>30$ pairs were used, as this is the recommended minimum number of pairs that can be used to calculate the Moran's I autocorrelation coefficient (Rossi et al. 1992). This resulted in the use of 16 lag-classes, with maximum lag distances of 21.5 and $10.8 \mathrm{~cm}$ for 4 and $2 \mathrm{~cm}$ distributions, respectively. Mean I-values for each lag-class set were tested for significance against the assumption of randomisation, as above for the global Moran's I-statistic, thus making it possible to highlight the distance classes in which significant spatial autocorrelation (positive or negative) were present. A correlogram, therefore, identifies the significant scales of spatial organisation which, in turn, can provide insight into the underlying structuring mechanisms that generated the distribution (Sokal \& Oden 1978). An overall test, using the Bonferroni correction for multiple tests (Oden 1984, Legendre \& Fortin 1989), was performed on the whole correlogram; only the results of significant correlograms are presented. Correlograms were constructed and significance tested using the correlogram routines of SAAP software (Spatial Autocorrelation Analysis Package 4.3, Exeter Software).

Fractal geometry: Fractal geometry was initially developed by Mandelbrot $(1977,1983)$ to describe the structure of complex patterns that could not be characterised by simple Euclidean approximations (e.g. lines, curves). The subsequent application of fractal geometry to marine systems is widely accepted (Frontier 1987, Sugihara \& May 1990). Here, we employ single-dimension fractal analysis to determine whether there is nonrandom structure in in vivo fluorescence distributions. In addition, fractal analysis characterises multiscale structure that can provide insight into the scale of origin and scale of subsequent propagation of structure.
The key component of fractal geometry is the concept of 'self-similarity'. An object or distribution is described as self-similar if structure at one scale can be decomposed into smaller copies of itself (Hastings \& Sugihara 1993), thereby indicating a relationship between structure at different scales over a continuum of scales and hence non-randomness. Details of the single dimension fractal analysis method we use here are given elsewhere (Seuront \& Lagadeuc 1997, Burrough 1981, 1983, Waters \& Mitchell 2002). Briefly, the method identifies the self-similarity of a variance measure over a range of scales. The variance measure employed is the lag-specific semivariance, $\gamma(h)$ (Eq. 3), where the lag is the separation distance between pairs of samples, as described earlier for the calculation of $I$ (subsection 'Moran's I-statistic'). The lag-specific semivariance $\gamma(h)$ was calculated utilising GS+ software (Geostatistics for the Environmental Sciences, Version 5.1.1, Gamma Designs) thus:

$$
\gamma(h)=\frac{1}{2 N(h)} \sum_{i=1}^{N(h)}[Z(i)-Z(i+h)]^{2}
$$

where $N(h)$ is the number of pairs of data points separated by lag $h$, and $Z(i)$ and $Z(i+h)$ are the recorded values at points $i$ and $i+h$. This method is a 1-dimensional fractal approach, the 2-dimensional distributions were therefore decomposed into sets of omnidirectional linear series prior to analysis. Calculated $\gamma(h)$ values are therefore the mean value for all possible pairings, irrespective of direction. To avoid the effects of low sample sizes in higher lag-classes, only lagclasses less than half of the total length of the data set were considered, as recommended by Journel \& Huijbregts (1978). The maximum values of $h$ were therefore 8.5 and $17.0 \mathrm{~cm}$ for the 4 and $2 \mathrm{~cm}$ distributions, respectively, resulting in 11 lag-distance classes. To calculate the fractal dimension $\left(D_{\mathrm{F}}\right)$, which characterises the relationship between the semivariance over a continuum of scales, a log-log semivariogram was constructed of $\gamma(h)$ against $h$ (see e.g. Figs. 2, 5 \& 6). A distribution is described as statistically self-similar, and therefore fractal, when there is significant log-log linear relationship between $\gamma(h)$ and $h$, i.e. scaledependence. $D_{\mathrm{F}}$ is estimated from the slope coefficient $(m)$ of this linear relationship (Eq. 4):

$$
D_{\mathrm{F}}=(4-m) / 2
$$

where $m$ was calculated using least-squares regression analysis (SPSS [subprogram of the Statistical Package for the Social Sciences] 10.0.5 statistical software). The scales over which scale-dependence was present, termed the scaling region, were identified as the range of $h$ values which maximised the regression analysis coefficient of determination $\left(\mathrm{r}^{2}\right)$. The standard error of $m$ was used to calculate $95 \%$ confi- 
dence intervals $(95 \% \mathrm{CI})$ for the $D_{\mathrm{F}}$ value. Distributions that lacked scale-dependence and therefore displayed no slope on the semivariogram (see e.g. Fig. 2A) were identified as random distributions and non-fractal (nf). For scale-dependent distributions, the $D_{\mathrm{F}}$ value characterises the nature of the spatial structure. Distributions with fractal dimensions that approach 1 are dominated by long-range effects, resulting in increased spatial complexity and strong scale-dependence. Conversely, distributions with $D_{\mathrm{F}}$ values approaching 2 are dominated by short-range structuring processes, such that small-scale variability smoothes out long-range effects, resulting in an even distribution of the semivariance over a continuum of scales and therefore weak scale-dependence (Burrough 1983).

\section{RESULTS}

Microscale sampling identified scale-dependence in distributions of in vivo fluorescence for all locations, sampler orientations and sample intervals. The structure of variability included steep gradients, discrete 'hot' spots (patches of elevated fluorescence) and 'cold' spots (discrete 'gaps'). Fig. 1 provides examples of these features.

\section{Comparison of sample orientation}

Horizontal and vertical in vivo fluorescence distributions sampled in the Port River with the $4 \mathrm{~cm}$ sampling device (Device I) were visibly similar on October 28 (Fig. 1C,D) and November 5 (Fig. 1E,F), implying similar structuring mechanisms operating in both directions. On October 26 (Fig. 1A,B), structure was dissimilar, suggesting disparate sources of structure in the horizontal and vertical. These observations were confirmed by fractal analysis, which identified scaledependence in the vertical but not the horizontal plane for October 26 distributions (Fig. 2A,B, Table 1), and a consistent absence and presence of scale-dependence in distributions sampled on October 28 (Fig. 2C,D, Table 1) and November 5 (Fig. 2E,F, Table 1), respectively. The length of the scaling region varied between sampling days (Fig. 2, Table 1). On November 5, scale-dependence occurred across all lag distances (Fig. 2E,F), in contrast to the vertical distribution on October 26, where the scaling region was reduced due to a loss of scale-dependence at low and high lag distances (Fig. 2B, Table 1). Only distributions sampled on November 5, when the scaling region extended across all lag distances, were determined to be non-random by autocorrelation analysis, i.e. significant global $I$-values and associated significant correlograms (Table 1,
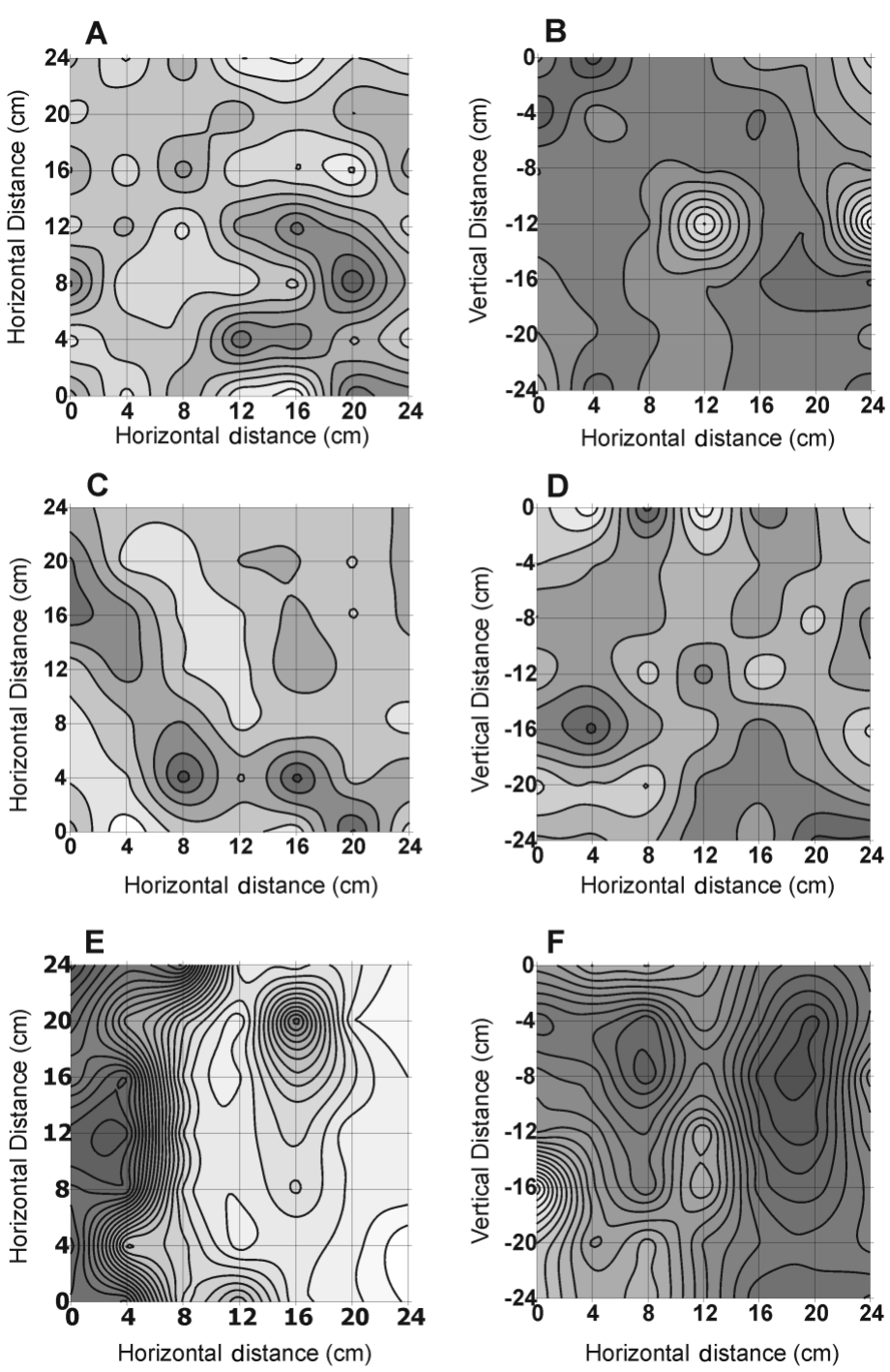

Fig. 1. Contour plots of 2-dimensional Port River in vivo fluorescence distributions sampled in horizontal (left-hand graphs) and vertical (right-hand graphs) orientation, within a $90 \mathrm{~min}$ period using Device I (4 cm sampling interval). Sampling dates (1998) were $(\mathrm{A}, \mathrm{B}) 26$ October, $(\mathrm{C}, \mathrm{D}) 28$ October, $(\mathrm{E}, \mathrm{F}) 5$ November. Contour shading shows data normalised to minimum (white) and maximum (black) values for each individual distribution; contours lines indicate $20 \%$ increase or decrease in the magnitude of in vivo fluorescence. Contour plots constructed using Surfer (6.04, Golden software) mapping software, employing a linear variogram kriging algorithm. Statistics given in Table 1

Fig. 3). Details of the structure for November 5 distributions were resolved by the correlogram analysis (Fig. 3), which identified a general trend of positive autocorrelation for samples separated by lag distances of less than $12.7 \mathrm{~cm}$ and a negative autocorrelation between samples separated by distances of greater than $19 \mathrm{~cm}$. This trend was the same for the horizontal and vertical planes. Generally, the November 5 vertical distribution was more structured than the hori- 

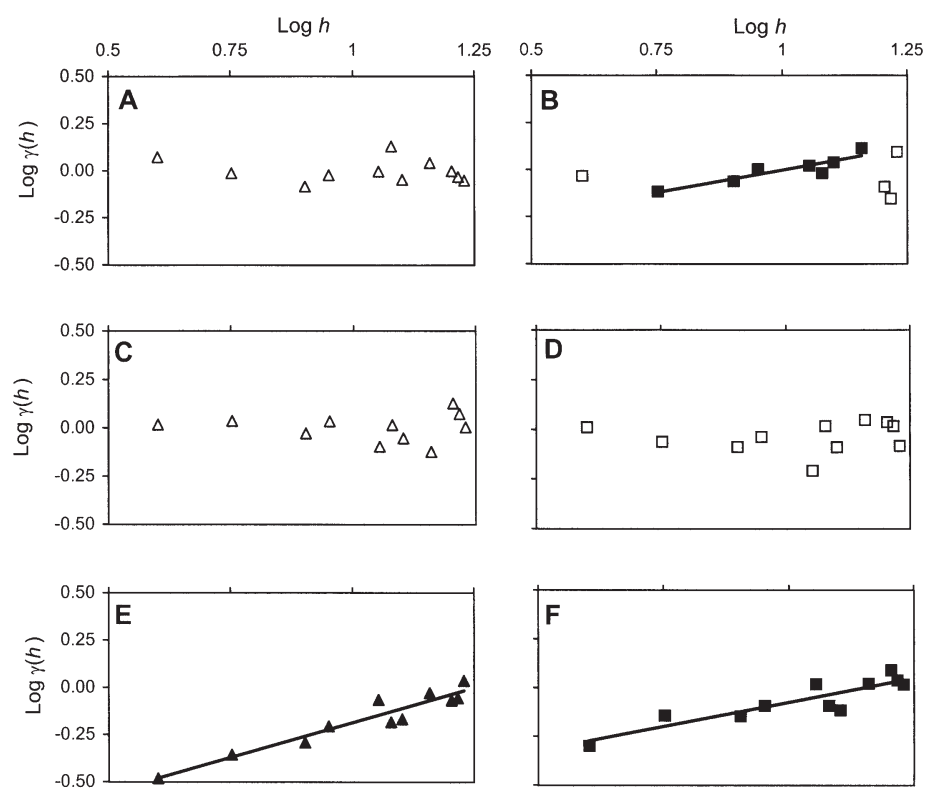

Fig. 2. Double logarithmic semivariograms, a plot of the semivariance $(\gamma(h))$ as a function of the lag $(h)$, of in vivo fluorescence distributions (Fig. 1) sampled in horizontal (left-hand graphs) and vertical (right-hand graphs) orientation within a $90 \mathrm{~min}$ period using Device I (4 cm sample interval). Sampling dates (1998) were $(\mathrm{A}, \mathrm{B}) 26$ October, $(\mathrm{C}, \mathrm{D}) 28$ October, $(\mathrm{E}, \mathrm{F}) 5$ November. Open and closed symbols: scale-independence and scale-dependence, respectively; continuous lines: scaling regions (i.e. scales over which scale-dependence occurred). Statistics given in Table 1

zontal distribution, as indicated by increased global $I$-values $(0.180$ vs 0.107$)$ and an increase in scaledependence $\left(D_{\mathrm{F}}=1.54\right.$ vs 1.73 : Table 1$)$.

\section{Comparison of sampling scale}

Structural similarity (e.g. Fig. 4A,B) and dissimilarity (e.g. Fig. 4C,D) were observed between 4 and $2 \mathrm{~cm}$ res- olution samples. Scale-dependence in $2 \mathrm{~cm}$ distributions was often significantly greater than in $4 \mathrm{~cm}$ distributions (Figs. 5 \& 6, Table 2). On July 13, both distributions lacked scale-dependence (Table 2, Fig. 6C,D). The presence of scale-dependence across all possible lags only occurred in the $2 \mathrm{~cm}$ distributions on April 28 and June 2 (Figs. 6B \& 5D, respectively, Table 2). For the remainder of the distributions, the scaling region originated at the minimum lag distance, but scale-dependence was lost at the higher lag distances (Figs. 5 \& 6, Table 2). As with the sample orientation data (foregoing subsection), only distributions that exhibited scale-dependence across all scales were taken to be globally autocorrelated (Table 2).

Disparity between the 4 and $2 \mathrm{~cm}$ distributions was found in the correlogram analysis, with all five $2 \mathrm{~cm}$ distributions generating significant correlograms, compared with a single $4 \mathrm{~cm}$ distribution on April 28 (Fig. 7). This contrasts with the sampling orientation comparison, where only globally autocorrelated distributions generated significant correlograms. The significant correlograms showed positive autocorrelation at low lags and either negative autocorrelation at high lags with the scaling region across all lags (Fig. 7B,E, $2 \mathrm{~cm}$ distributions), or negative autocorrelation at middle lags (Fig. 7A,C, $2 \mathrm{~cm}$ distributions) with shortened scaling regions. In the latter case, scale-dependence turned to noise at higher lags. Some correlograms lacked scale-dependence and were categorised as non-fractal (nf) (Fig. 7D,F, Table 2).

\section{Comparison of sampling sites}

The mean $w^{\prime}$ for the Port River site was $5.63 \mathrm{~m}^{2} \mathrm{~s}^{-2}$ (Tables 1 \& 2) compared with $39.8 \mathrm{~m}^{2} \mathrm{~s}^{-2}$ at Port Noarlunga (Table 2). All sample sets collected in the Port River displayed significant scale-dependence $\left(D_{\mathrm{F}}<2\right)$, in contrast to only 1 of the Port Noarlunga

Table 1. Comparison of sampling-device orientation (Port River). Characterisation of the physical environment $\left(w^{\prime}\right)$, together with results of fractal and spatial autocorrelation analysis for 2-dimensional in vivo fluorescence distributions, sampled in the horizontal (H) and vertical (V) plane with Device I (4 cm sample interval). Fractal dimension data are means with $95 \%$ CI limits in patentheses. Details of all calculations are provided in 'Materials and methods'. nf: non-fractal; ns: not significant

\begin{tabular}{|c|c|c|c|c|c|c|c|c|}
\hline \multirow[t]{2}{*}{$\begin{array}{l}\text { Sampling date } \\
\text { (1998) }\end{array}$} & \multicolumn{2}{|c|}{$\begin{array}{c}W^{\prime} \\
\left(\mathrm{cm} \mathrm{s}^{-1}\right)\end{array}$} & \multicolumn{2}{|c|}{$\begin{array}{l}\text { Fractal dimension } \\
\text { (95\% CI limits) }\end{array}$} & \multicolumn{2}{|c|}{$\begin{array}{l}\text { Scaling region } \\
\qquad(\mathrm{cm})\end{array}$} & \multicolumn{2}{|c|}{$\begin{array}{c}\text { Global } \\
\text { autocorrelation, } I \\
\text { (p-value) }\end{array}$} \\
\hline & $\mathrm{H}$ & V & $\mathrm{H}$ & V & $\mathrm{H}$ & $\mathrm{V}$ & $\mathrm{H}$ & $\mathrm{V}$ \\
\hline 26 October & 0.12 & 0.06 & $\mathrm{nf}$ & $\begin{array}{c}1.76 \\
(1.71-1.81)\end{array}$ & $\mathrm{nf}$ & $5.7-14.4$ & $\begin{array}{c}-0.032 \\
\text { (ns) }\end{array}$ & 0.011 \\
\hline 28 October & 12.9 & 16.6 & $\mathrm{nf}$ & $\mathrm{nf}$ & $\mathrm{nf}$ & $\mathrm{nf}$ & $\begin{array}{l}-0.035 \\
\text { (ns) }\end{array}$ & $\begin{array}{c}-0.028 \\
\text { (ns) }\end{array}$ \\
\hline 05 November & 0.07 & 0.78 & $\begin{array}{c}1.54 \\
(1.51-1.58)\end{array}$ & $\begin{array}{c}1.73 \\
(1.70-1.76)\end{array}$ & $4-17$ & $4-17$ & $\begin{array}{c}0.180 \\
(<0.001)\end{array}$ & $\begin{array}{c}0.107 \\
(<0.001)\end{array}$ \\
\hline
\end{tabular}



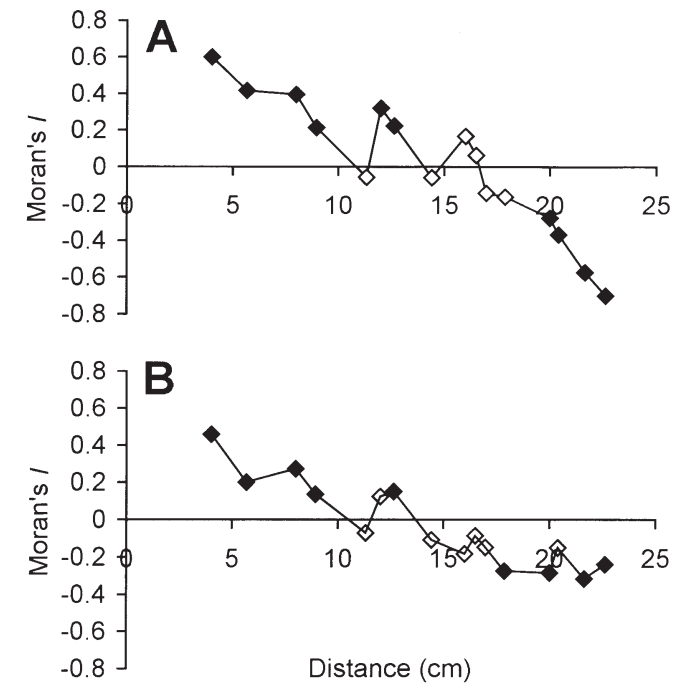

Fig. 3. Omnidirectional spatial correlograms of in vivo fluorescence distributions measured in (A) horizontal and (B) vertical planes with Device I in Port River environment on 5 November 1998. Open and closed symbols: non-significant and significant Moran's $I$-values at the $\alpha=0.05$ level, respectively
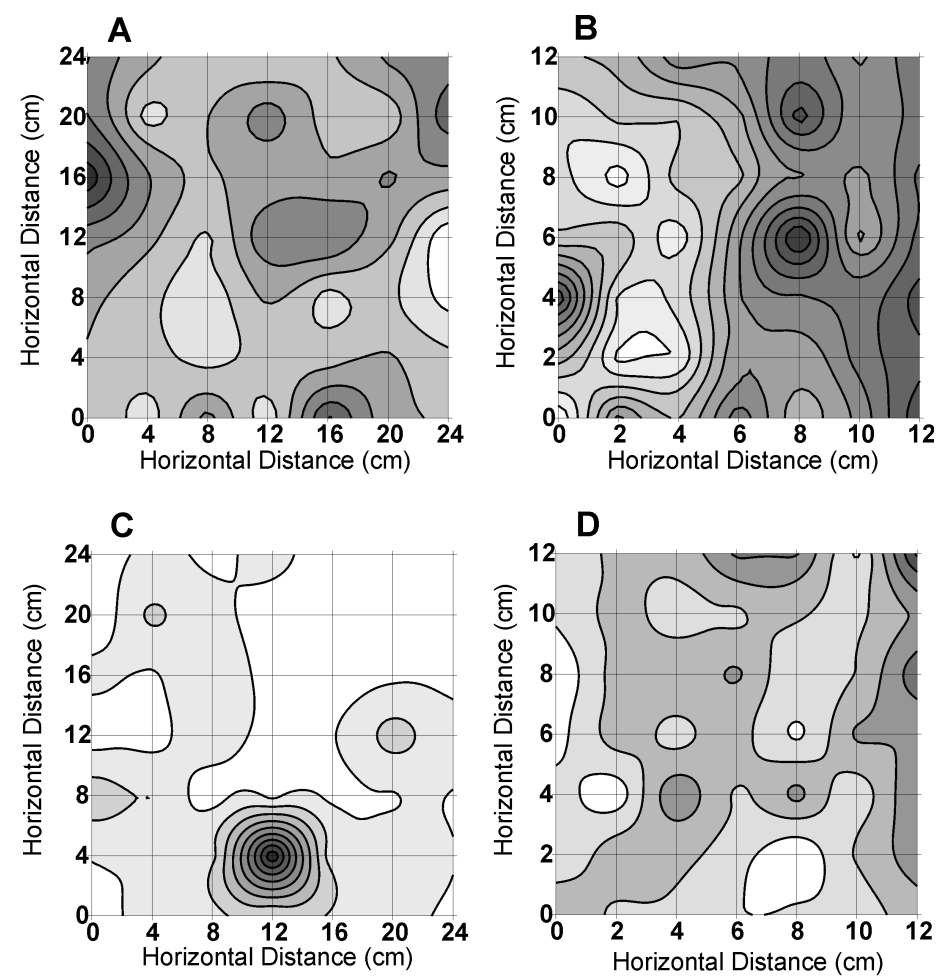

Fig. 4. Example contour plots of 2-dimensional in vivo fluorescence distributions measured with Device I ( $4 \mathrm{~cm}$ sample interval, right-hand graphs) and Device II (2 cm sample interval, left-hand graphs), within a 90 min period. Sampling locations and dates (1999) were (A,B) Port Noarlunga on 2 June and (C,D) Port River on 13 July. Contour shading and contour intervals as in Fig. 1. Contour plots were constructed using Surfer (6.04, Golden software) mapping software, employing a linear variogram kriging algorithm. Statistics given in Table 2 sampling events (April 28, $2 \mathrm{~cm}$ interval: Table 2). This apparent increase in structural complexity in Port River distribution was not, however, confirmed by the autocorrelation analyses, which identified approximately equal occurrences of non-random distributions (global $I$ ) and significant correlograms for both environments (Table 2, Fig. 7). There was no correlation between calculated $W^{\prime}$ values and the values of $D_{\mathrm{F}}(\mathrm{r}=-0.26, \mathrm{p}=0.057)$ or global $I(\mathrm{r}=$ $-0.25, \mathrm{p}=0.29$ ).

\section{DISCUSSION}

Two-dimensional fluorescence distributions were non-random and exhibited scale-dependence. These results are consistent with those of previous investigations (Waters \& Mitchell 2002) on a 1-dimensional centimetre scale and expand the documentation to 2 dimensions. The results (Tables $1 \& 2$ ) add to a growing consensus that non-random phytoplankton spatial structure is a common feature of the planktonic microenvironment (Cassie 1959, Derenbach et al. 1979, Mitchell \& Fuhrman 1989, Owen 1989, Cowles \& Desiderio 1993, Jaffe et al. 1998, Waters \& Mitchell 2002). The concept that structure arises at large scales and propagates to smaller scales is challenged by our
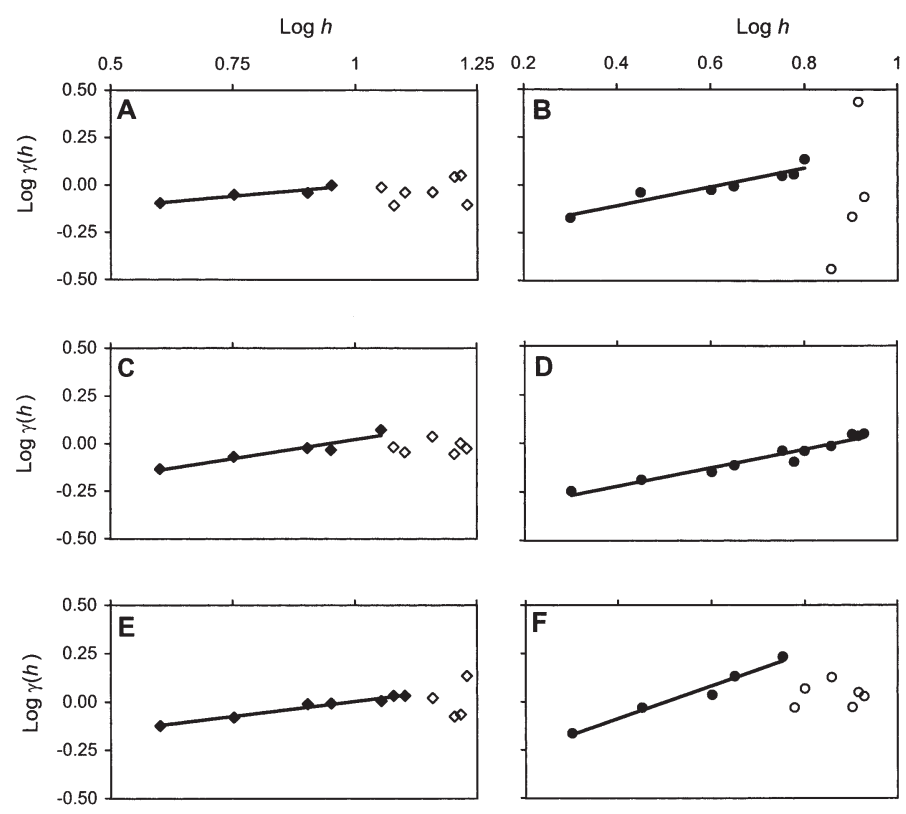

Fig. 5. Double logarithmic semivariograms, a plot of the semivariance $(\gamma(h))$ as a function of the lag $(h)$, of in vivo fluorescence distributions sampled with Device I $(4 \mathrm{~cm})$ and Device II $(2 \mathrm{~cm})$, within a 90 min period in Port River. Sampling dates (1999) were $(A, B) 20$ May, (C,D) 2 June and (E,F) 15 July. Open and closed symbols: scale-independence and scale-dependence, respectively; continuous lines: scaling regions 


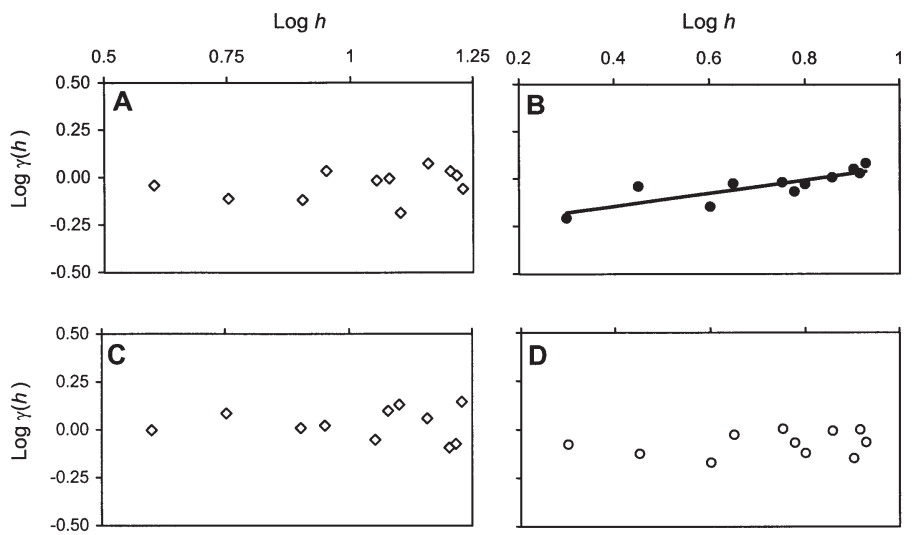

Fig. 6. Double logarithmic semivariograms, a plot of the semivariance $(\gamma(h))$ as a function of the lag $(h)$, of in vivo fluorescence distributions sampled with Device I $(4 \mathrm{~cm})$ and Device II $(2 \mathrm{~cm})$, within a 90 min period at Port Noarlunga. Sampling dates (1999) were $(A, B) 28$ April and $(C, D) 13$ July. Open and closed symbols: scale-independence and scale-dependence, respectively; continuous line: scaling regions

finding of greater structure for the $4 \mathrm{~cm}$ resolution distributions than for the $2 \mathrm{~cm}$ resolution distributions. An appraisal of the analysis techniques and implications of these results for future microscale plankton studies are discussed below.

The extent of structure detected depended on the analysis method. Fractal geometry appears to be the most informative measure of structure, because it allows direct comparison of fluorescence distributions between habitats, locations and seasons, as well as identifying the length of the scaling region (e.g. Tables 1 \& 2). We calculated a single fractal dimension because multifractal analysis requires high-order statistical moments, making it data-intensive. The hundreds to thousands of points necessary for the multifractal approach should be a goal for plankton distributions since it provides additional information including an estimate of intermittency (Seuront et al. 1999, 2002).

In comparison to the fractal dimension, the global I-statistic only identified non-random structure in distributions where scale-dependence extended across all lag distances. This means that the statistic is sensitive to the total length of the sample area and will not identify structure in distributions that are scaledependent at low lags and become scale-independent at higher lags (e.g. Fig. 7A,C, Table 1: May 20, $2 \mathrm{~cm}$ and July 15, $2 \mathrm{~cm}$ ). The Moran's $I$-statistic is also sensitive to joint departures of data pairs from the mean (Eq. 2). For distributions with low variability (e.g. Fig. 4A), Moran's $I$ is near zero and not significant. It may be for this reason that the correlograms of the $4 \mathrm{~cm}$ distributions in the Port River were not significant despite being resolved by the fractal dimension (Table 2). The significant correlograms are a useful tool for identifying the 'shape' of the spatial structure (Legendre \& Fortin 1989, Legendre \& Legendre 1998). For example, a continuous decrease across the correlogram is indicative of a gradient, including gradients across the whole distribution (e.g. Figs. 1E \& 3A), around aggregates or on the borders of regions of elevated biomass (e.g. Figs. 4B \& 7). In contrast the alter-

Table 2. Comparison of sampling intervals. Characterisation of physical environment $\left(w^{\prime}\right)$ together with results of fractal and spatial autocorrelation analysis for 2-dimensional in vivo fluorescence distributions sampled with Device I $(4 \mathrm{~cm}$ interval) and Device II ( $2 \mathrm{~cm}$ interval). Fractal dimension data are means with $95 \%$ CI limits in parentheses. Details of all calculations are provided in the 'Materials and methods'. nf: non-fractal; ns: not significant

\begin{tabular}{|c|c|c|c|c|c|c|c|c|}
\hline \multirow[t]{2}{*}{ Sampling date } & \multicolumn{2}{|c|}{$\begin{array}{c}W^{\prime} \\
\left(\mathrm{cm} \mathrm{s}^{-1}\right)\end{array}$} & \multicolumn{2}{|c|}{$\begin{array}{l}\text { Fractal dimension } \\
\text { (95\% CI limits) }\end{array}$} & \multicolumn{2}{|c|}{$\begin{array}{l}\text { Scaling region } \\
(\mathrm{cm})\end{array}$} & \multicolumn{2}{|c|}{$\begin{array}{c}\text { Global } \\
\text { autocorrelation I } \\
\text { (p-value) }\end{array}$} \\
\hline & $4 \mathrm{~cm}$ & $2 \mathrm{~cm}$ & $4 \mathrm{~cm}$ & $2 \mathrm{~cm}$ & $4 \mathrm{~cm}$ & $2 \mathrm{~cm}$ & $4 \mathrm{~cm}$ & $2 \mathrm{~cm}$ \\
\hline \multicolumn{9}{|l|}{ Port River } \\
\hline 20 May 99 & 10.4 & $0.84^{\mathrm{a}}$ & $\begin{array}{c}1.89 \\
(1.86-1.91)\end{array}$ & $\begin{array}{c}1.75^{\mathrm{a}} \\
(1.72-1.79)\end{array}$ & $4-8.9$ & $2-6.3^{\mathrm{a}}$ & $\begin{array}{l}0.00048 \\
(\mathrm{~ns})\end{array}$ & $\begin{array}{l}0.045^{\mathrm{a}} \\
(\mathrm{ns})\end{array}$ \\
\hline 2 June 99 & 0.51 & 0.06 & $\begin{array}{c}1.80 \\
(1.76-1.84)\end{array}$ & $\begin{array}{c}1.76 \\
(1.74-1.78)\end{array}$ & $4-11.3$ & $2-8.5$ & $\begin{array}{l}0.00052 \\
\text { (ns) }\end{array}$ & $\begin{array}{c}0.120 \\
(<0.001)\end{array}$ \\
\hline 15 July 99 & 11.0 & 21.1 & $\begin{array}{c}1.84 \\
(1.83-1.86)\end{array}$ & $\begin{array}{c}1.58 \\
(1.53-1.62)\end{array}$ & $4-12.6$ & $2-5.6$ & $\begin{array}{c}0.025 \\
\text { (ns) }\end{array}$ & $\begin{array}{c}0.027 \\
\text { (ns) }\end{array}$ \\
\hline \multicolumn{9}{|l|}{ Port Noarlunga } \\
\hline 28 April 99 & 42.88 & 41.98 & $\mathrm{nf}$ & $\begin{array}{c}1.83 \\
(1.79-1.86)\end{array}$ & $\mathrm{nf}$ & $2-8.5$ & $\begin{array}{c}-0.011 \\
\text { (ns) }\end{array}$ & $\begin{array}{c}0.082 \\
(<0.01)\end{array}$ \\
\hline 13 July 99 & 35.21 & 39.82 & $\mathrm{nf}$ & $\mathrm{nf}$ & $\mathrm{nf}$ & $\mathrm{nf}$ & $\begin{array}{c}0.012 \\
\text { (ns) }\end{array}$ & $\begin{array}{c}0.014 \\
\text { (ns) }\end{array}$ \\
\hline
\end{tabular}



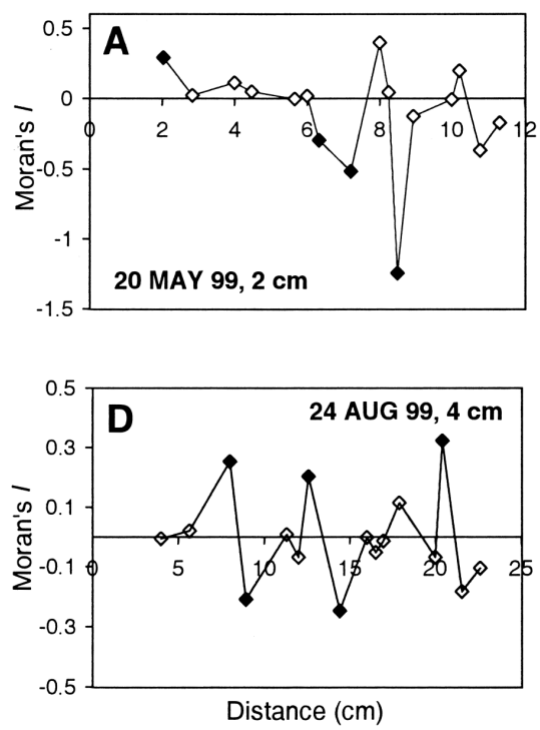
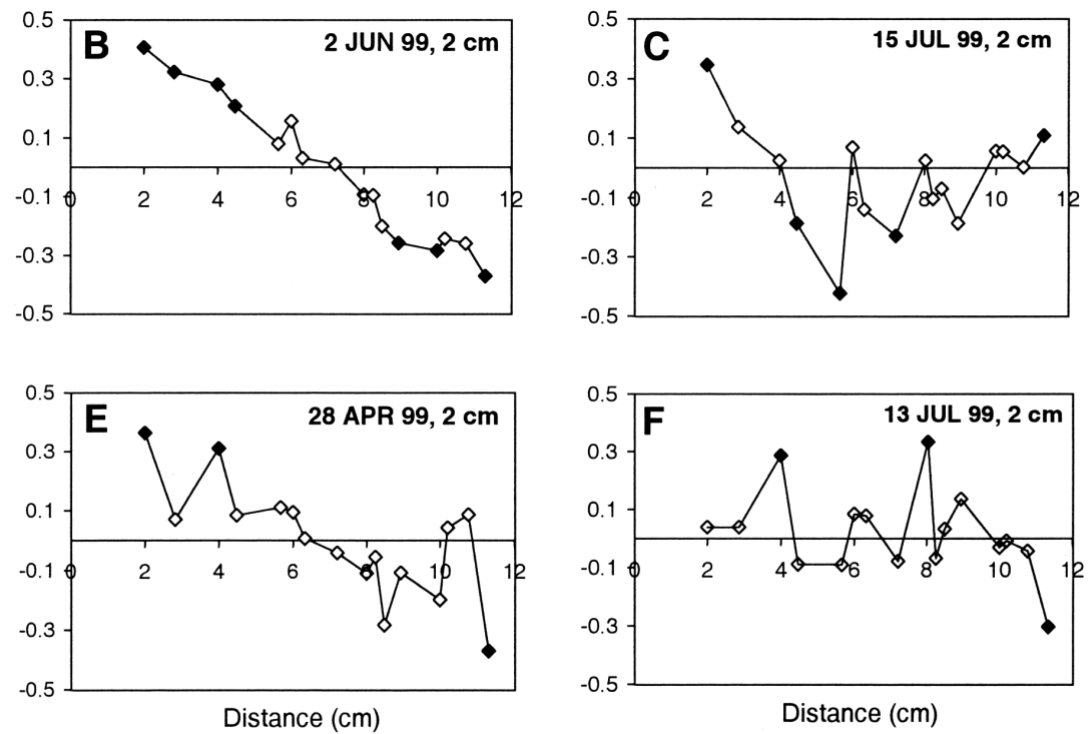

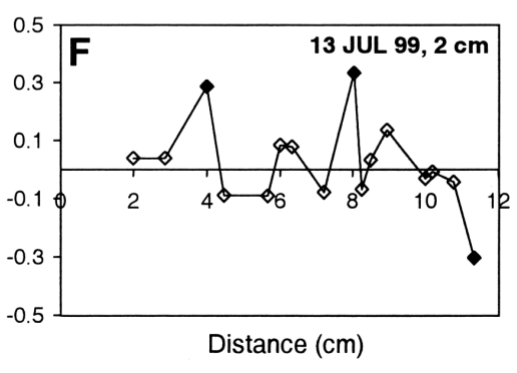

Fig. 7. Omnidirectional correlograms of in vivo fluorescence distributions in Table 2. Only significant correlograms, as determined by Bonferroni correction method (see 'Materials and methods'), are presented. Sampling locations were (A to D) Port River and $(\mathrm{E}, \mathrm{F})$ Port Noarlunga. Axes and symbols as in Fig. 3. Sampling date and inter-sample distance (cm) are shown in each graph

nation of positive and negative $I$-values (e.g. Figs. 4D \& $7 F)$ is indicative of the presence of 'hotspots' and 'coldspots' in the distribution, indicating randomness.

The greater structural complexity at $2 \mathrm{~cm}$ than at $4 \mathrm{~cm}$ is the first empirical evidence that structural complexity increases as microscale sampling-resolution increases. This creates a conflict in the apparent source of spatial structure in phytoplankton distributions. The long-standing assumption has been that turbulence transfers variability generated at large scales down to small scales via the turbulent energy cascade (Denman et al. 1977, Owen 1989). Our results imply, however, that the centimetre scale is an additional source of structure that may propagate up to larger scales, introducing variability from the opposite direction. We recognise that we have provided only a limited dataset, due to the time-intensive nature of the sample collection and processes. How representative these data are of the planktonic ecosystem is yet to be determined. It is our aim to use the present findings as the basis of future studies addressing whether structure is generated at small scales and propagates to larger scales, cascades down from above, or is created by a combination of the two.

The observation of structure implies that mechanisms exist that are capable of generating 2-dimensional structure at small scales. The interaction of cell morphology, motility and in situ mixing is one set of interactions that can create structure (e.g. Kessler 1985, Mitchell et al. 1990) as discussed in detail by Waters \& Mitchell (2002). Young et al. (2001) modelled the generation of microscale structure as a function of an asymmetrical growth model. The incorporation of mixing into the model showed that clusters were not destroyed, instead they were drawn out into tendrils of elevated biomass, similar to the structures resolved by correlogram analysis in the results presented here (Fig. 4), and we infer that this may be one underlying process. Additional mechanisms may modify existing structure. For example, zooplankton grazing has been proposed to reduce structure at the metre scale, as indicated by flattening of the variance spectra of fluorescence (Abraham 1998, Lovejoy et al. 2001). In the absence of sufficient physical structure data and measures of the rates of biological processes, we are unable to comment on the relative importance of physical and biological structuring mechanisms in creating the structure observed herein. Our results suggest that there is an increase in spatial complexity in Port River (high-chlorophyll, low-energy environment) compared with the Port Noarlunga site (low-chlorophyll, highenergy environment). This comparison is, however, based on limited datasets and requires further sampling to test its generality. We predict that mixing and phytoplankton abundance will directly affect spatial structure. We envisage that these results will provide the impetus to seek the dominant-structuring mechanisms in future studies.

The range of structural patterns, from highly scaledependent to random, suggests that the observed structure is not a sampling artefact. While we recognise that sampling with syringes may cause some distortion of the structure, including disintegration of aggregations and averaging across the sample volume 
of the individual syringe, we feel that these effects would reduce the variation in structure observed, rather than create it. In addition, the collection of water samples in this manner allows determination of the taxonomic distribution of cells (by direct cell counts) and analysis of spatial variation in cell physiology (e.g. determination of cell viability using flow-cytometric techniques; Brussard et al. 2001). The advantage of the sample collection method here over alternative 2-dimensional in situ sampling methods, including holography (Katz et al. 1999, Hobson et al. 2000) and laser-sheet fluorometry (Franks \& Jaffe 2001), is that land-based instrumentation used to quantify phytoplankton biomass has a higher sensitivity and will therefore record the fluorescent signal of particles that are below the detection limits of in situ imaging systems. Katz et al. (1999) reported the presence of some structure in microscale distributions of diatom cells; however, their descriptions were purely qualitative. Franks \& Jaffe (2001) quantified the spatial structure of fluorescence in an open-water environment using spectral analysis, and reported that distributions were consistently random; however, fluorescent targets were identified as aggregates and the contents of copepod guts, which represent only the largest size category of fluorescent particles. The fluorescence signal may have been further modified by the orientation of the target, by the masking effects of copepod body parts, and the presence of particles in the $1 \mathrm{~m}$ space between the laser sheet and the sensor. For these reasons, non-random spatial structure similar to that reported here may not have been detected.

This study constitutes the first quantification of spatial structure in centimetre-scale 2-dimensional fluorescence distributions. The extent of structure at these scales requires further investigation. Herein we have proposed a methodological framework for future centimetre-scale fluorescence distribution studies. We predict that as interest in the planktonic microscale continues to increase (Azam 1998), and technological advances improve the resolution of sampling techniques (e.g. Wolk et al. 2002), microscale spatial structure may be revealed to be a consistent feature of the planktonic environment.

Acknowledgements. We are very grateful to D. Edyvean for his construction of the syringe sampling devices. We are also thankful to M. Hale and L. Pearson for assistance in the field, and to the captain of the 'Port Princess' tourist vessel for access to the Port River field site. In addition we would like to offer our thanks to L. Seuront for verifying the correct use and interpretation of the fractal analysis techniques employed. The helpful suggestions and comments provided by M. Hale and 4 anonymous reviewers greatly improved the quality of the manuscript. Funding for this research was provided by the Australian Research Council (ARC grant to J.G.M.). R.L.W. was supported by an Australian Postgraduate Award (APA).

\section{LITERATURE CITED}

Abraham ER (1998) The generation of plankton patchiness by turbulent stirring. Nature 391:577-580

Azam F (1998) Microbial control of oceanic carbon flux: the plot thickens. Nature 280:694-696

Baker AL, Baker KK, Tyler PA (1985) A family of pneumatically-operated thin layer samplers for replicate sampling of heterogeneous water columns. Hydrobiologia 122: 207-211

Burrough PA (1981) Fractal dimensions of landscapes and other environmental data. Nature 294:240-242

Burrough PA (1983) Multiscale sources of spatial variation in soil. I. The application of fractal concepts to nested levels of soil variation. J Soil Sci 43:577-597

Cassie RM (1959) Micro-distribution of plankton. NZ J Sci 2:398-409

Cliff AD, Ord JK (1981) Spatial processes: models and applications. Pion, London

Cowles TJ, Desiderio RA (1993) Resolution of biological microstructure through in situ fluorescence emission spectra. Oceanography 6:105-111

Currie WJS, Clareboudt MR, Roff JC (1998) Gaps and patches in the ocean: a one-dimensional analysis of planktonic distributions. Mar Ecol Prog Ser 171:15-21

Denman KL, Powell TM (1984) Effects of physical processes on planktonic ecosystems in coastal ocean. Oceanogr Mar Biol Annu Rev 22:125-168

Denman KL, Okubo A, Platt T (1977) The chlorophyll fluctuation spectrum in the sea. Limnol Oceanogr 22:1033-1038

Derenbach JB, Astheimer H, Hansen HP, Leach H (1979) Vertical microscale distribution of phytoplankton in relation to the thermocline. Mar Ecol Prog Ser 1:187-193

Franks PJS, Jaffe JS (2001) Microscale distributions of phytoplankton: initial results from two-dimensional imaging fluorometer, OSST. Mar Ecol Prog Ser 220:59-72

Frontier S (1987) Applications of fractal theory to ecology. In: Legendre P, Legendre L (eds) Developments in numerical ecology. Springer-Verlag, Berlin, p 335-378

Hastings HM, Sugihara GS (1993) Fractals: a user's guide for the natural sciences. Oxford University Press, Oxford

Hobson PR, Lampitt RS, Rogerson A, Watson J, Fang X, Krantz EP (2000) Three-dimensional spatial coordinates of individual plankton determined using underwater hologrammetry. Limnol Oceanogr 45:1167-1174

Jaffe JS, Franks PJS, Leising AW (1998) Simultaneous imaging of phytoplankton and zooplankton distributions. Oceanography 11:24-29

Journel AC, Huijbregts CJ (1978) Mining geostatistics. Academic Press, London

Katz J, Donaghay PL, Zang J, King S, Russell K (1999) Submersible holocamera for detection of particle characteristics and motions in the ocean. Deep-Sea Res 46:1455-1481

Kessler J (1985) Hydrodynamic focussing of motile algal cells. Nature 313:218-220

Kolmogorov AN (1941) The local structure of turbulence in incompressible viscous fluid with very large Reynolds numbers. Dokl Akad Nauk SSSR 30:299-303

Kundu PK (1990) Fluid mechanics. Academic Press, San Diego

Legendre P, Fortin MJ (1989) Spatial pattern and ecological analysis. Vegetatio 80:107-138

Legendre P, Legendre L (1998) Numerical ecology, 2nd edn. Elsevier Science, Amsterdam

Lovejoy S, Currie WJS, Tessier Y, Claerboudt MR, Bourget E, Roff JC, Schertzer D (2001) Universal multifractals and ocean patchiness: phytoplankton, physical fields and coastal heterogeneity. J Plankton Res 23:117-141 
Mandelbrot B (1977) Fractals: form, chance and dimension. WH Freeman, London

Mandelbrot B (1983) The fractal geometry of nature. WH Freeman, New York

Mitchell JG, Fuhrman JA (1989) Centimeter scale vertical heterogeneity in bacteria and chlorophyll a. Mar Ecol Prog Ser 54:141-148

Mitchell JG, Okubo A, Fuhrman JA (1990) Gyrotaxis as a new mechanism of generating spatial heterogeneity and migration in microplankton. Limnol Oceanogr 35:123-130

Moran PAP (1950) Notes on continuous stochastic phenomena. Biometrika 37:17-23

Oden NL (1984) Assessing the significance of a spatial correlogram. Geogr Anal 16:1-16

Okubo A (1978) Horizontal dispersion and critical scales for phytoplankton patches. In: Steele JH (ed) Spatial pattern in plankton communities. Plenum Press, New York

Okubo A (1980) Diffusion and ecological problems: mathematical models. Springer-Verlag, Berlin

Owen RW (1989) Microscale and finescale variations of small plankton in coastal and pelagic environments. J Mar Res 47:197-240

Pascual M, Ascioti FA, Caswell H (1995) Intermittency in the plankton: a multifractal analysis of zooplankton biomass variability. J Plankton Res 17:1209-1232

Platt T (1972) Local phytoplankton abundance and turbulence. Deep-Sea Res 19:183-187

Platt T, Denman KL (1975) Spectral analysis in ecology. Annu Rev Ecol Syst 6:189-210

Powell TM, Okubo A (1994) Turbulence, diffusion and patchiness in the sea. Phil Trans R Soc Lond Biol Sci 343:11-18

Rossi RE, Mulla DJ, Journel AG, Franz EH (1992) Geostatistical tools for modeling and interpreting ecological spatial dependence. Ecol Monogr 62:277-314

Editorial responsibility: Otto Kinne (Editor),

Oldendorf/Luhe, Germany
Seuront L, Lagadeuc Y (1997) Characterisation of spacetime variability in stratified and mixed coastal waters (Baie des Chaleurs, Quebec, Canada): application of fractal theory. Mar Ecol Prog Ser 159:81-95

Seuront L, Schmitt F, Lagadeuc Y, Schertzer D, Lovejoy S (1996) Multifractal analysis of phytoplankton biomass and temperature in the ocean. Geophys Res Lett 23:3591-3594

Seuront L, Schmitt F, Lagadeuc Y, Schertzer D, Lovejoy S (1999) Universal multifractal analysis as a tool to characterize multiscale intermittent patterns: example of phytoplankton distribution in turbulent coastal waters. J Plankton Res 21:877-922

Seuront L, Gentilhomme V, Lagadeuc Y (2002) Small-scale nutrient patches in tidally mixed coastal waters. Mar Ecol Prog Ser 232:29-44

Sokal RR, Oden NL (1978) Spatial autocorrelation in biology 1: methodology. Biol J Linn Soc 10:199-228

Steele JH (1978) Some comments on plankton patches. In: Steele JH (ed) Spatial pattern in plankton communities. Plenum Press, New York, p 1-20

Strutton PG, Mitchell JG, Parslow JS (1996) Non-linear analysis of chlorophyll a transects as a method of quantifying spatial structure. J Plankton Res 18:1717-1726

Sugihara G, May RM (1990) Applications of fractals in ecology. Trends Ecol Evol 5:79-86

Waters RL, Mitchell JG (2002) The centimetre-scale spatial structure of estuarine in vivo fluorescence profiles. Mar Ecol Prog Ser 237:51-63

Wolk F, Yamazaki H, Seuront L, Lueck RG (2002) A freefall profiler for measuring bio-physical microstructure. J Atmos Oceanic Technol 19:780-793

Young WR, Roberts AJ, Stuhne G (2001) Reproductive pair correlations and the clustering of organisms. Nature 412 : $328-331$

Submitted: April 24, 2002; Accepted: December 17, 2002

Proofs received from author(s): March 10, 2003 